\title{
Erratum to: Autonomous construction using scarce resources in unknown environments
}

\section{Stéphane Magnenat • Roland Philippsen ·} Francesco Mondada

Published online: 1 June 2012

(C) Springer Science+Business Media, LLC 2012

Erratum to: Auton Robot

DOI 10.1007/s10514-012-9296-x
Following is corrected version of Fig. 2:

Fig. 2 The marXbot robot (top) and the details of the magnetic manipulator (bottom)
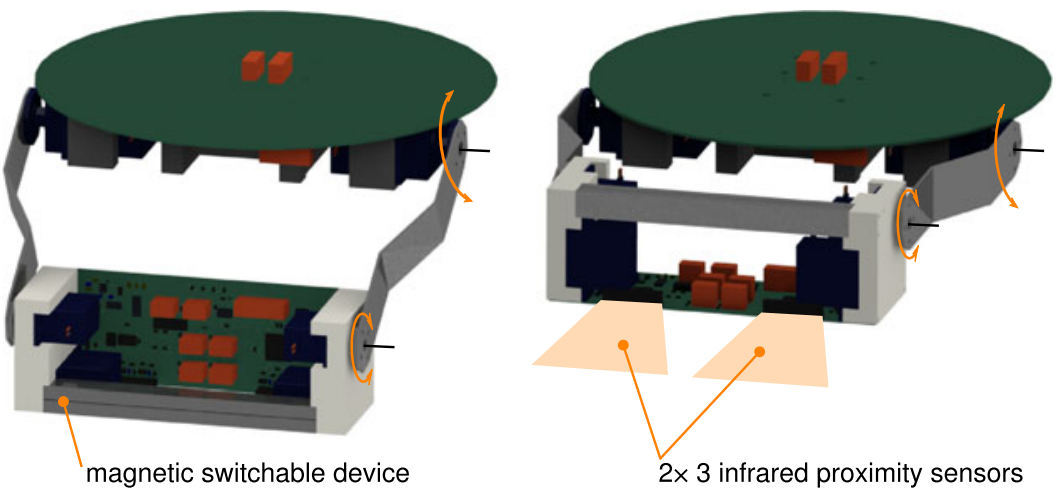

Principle and implementation of the magnetic switchable device
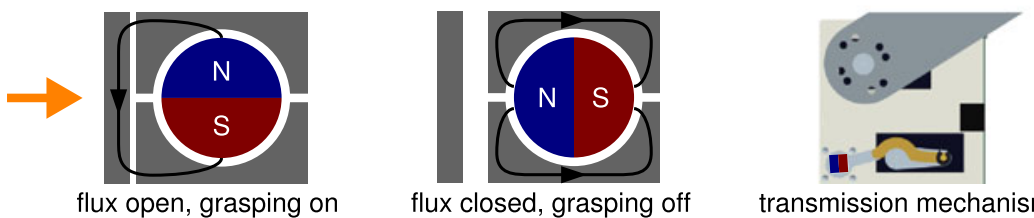

transmission mechanism

The online version of the original article can be found under doi:10.1007/s10514-012-9296-x.

\footnotetext{
S. Magnenat ( $\square)$

Autonomous System Lab, ETH Zentrum CLA E31,

Tannenstrasse 3, 8092 Zurich, Switzerland

e-mail: stephane@magnenat.net
}

R. Philippsen

Intelligent Systems Laboratory, Halmstad University, Halmstad,

Sweden

e-mail: roland.philippsen@hh.se

F. Mondada

EPFL-LSRO, Station 9, CH-1015 Lausanne, Switzerland

e-mail: francesco.mondada@epfl.ch 